Key words: Involuntary hospital treatment (IHT), Epidemiology, Schizophrenic psychosis.

\title{
Involuntary psychiatric admissions: A retrospective study of 460 cases
}

\section{P. Zeppegno* \\ P. Airoldi* \\ E. Manzetti* \\ M. Panella** \\ M. Renna** \\ E. Torre*}

* Cattedra di Psichiatria, Department of Medical Sciences, Medical school of Novara, University of Eastern Piedmont, "Amedeo Avogadro", Novara

** School of Hygiene and Public Health, Department of Medical Sciences, University of Eastern Piedmont, "Amedeo Avogadro", Novara

ITALY

\begin{abstract}
Introduction: We collected the data relating to involuntary hospital treatment (IHT) in the University Psychiatric Ward at Novara Hospital between 1991 and 2002, and compared them with those relating to Piedmont and the whole of Italy.

Methods: The data were collected from the ward medical records.

Results: IHT was much more frequent among young male schizophrenics living with their families of origin. Most of the subjects were not working at the time of admission. There was a statistically significant correlation between male gender and the risk of being admitted for a period of less than 12 days. The risk of being admitted for more than 12 days significantly correlated with the province of birth and residence, as well as with a diagnosis of schizophrenic psychosis.

Conclusions: Schizophrenia is the diagnosis that is most frequently associated with IHT.
\end{abstract}

\section{Introduction}

The use of involuntary hospital treatment (IHT) for schizophrenic subjects has been widely studied (Munk-Jorgensen, Mortensen \& Machon 1991, Kozumplik, Jukic \& Goreta 2003, Steinert \& Schmid 2004, Hattori \& Higashi 2004). Schizophrenia is still the diagnosis that has the greatest influence on 
the decision to hospitalize (Giampieri et al. 1993, Slagg 1993, Schnyder et al. 1999, Way \& Banks 2001, Wingerson et al. 2001), and it has also been demonstrated that schizophrenic subjects undergoing IHT treatment require longer admissions than those undergoing voluntary treatment (Arcuni \& Asaad 1989).

Some authors have highlighted the most frequently encountered characteristics of subjects undergoing IHT: a low average level of education, a prevalence of unmarried men and married women, and a large number of unemployed among men and housewives among women (Sostero et al. 1993).

However, there are few published studies describing the phenomenon as a whole in a hospital psychiatric ward (Sanguineti et al. 1996), partially because of the different legislation governing the subject in different countries: $91.7 \%$ of European countries have their own regulations concerning psychiatric legislation (WHO, 2001). Italy is in a peculiar position because it no longer has psychiatric hospitals, but an organisation based on the presence of psychiatric wards inside general hospitals, furthermore, the Italian regulations governing IHT do not consider the concept of dangerousness. Italian psychiatric legislation (Law No. 833 of 23 December 1978) foresees the possibility of IHT for a (renewable) period of seven days in the simultaneous presence of the following conditions:

1. the psychic alterations are such as to require urgent therapeutic interventions;

2. the therapeutic interventions are not accepted by the patient;

3. the circumstances do not allow the adoption of timely and suitable extra-hospital health measures.
The organisation of Italian psychiatric services subdivides the country into Mental Health Departments based on hospital psychiatric wards and mental health centres, which include residential communities, apartment groups, day centres and day hospitals (Piccinelli, Politi \& Barale 2002). Urgent services are provided in hospital psychiatric wards, local psychiatric outpatient clinics, general hospital Emergency Departments or at home Italy currently has the following number of psychiatric beds: $0.7 / 10,000$ inhabitants in general hospital psychiatric wards; $0.9 / 10,000$ in private psychiatric clinics; $0.1 / 10,000$ in day hospitals; and 3/10,000 in non-hospital residential facilities. The mental health staff allotment is $0.81 / 1,500$ area residents $(0,13 / 1,500$ psychiatrists, $0.05 / 1,500$ psychologists, and 0.41/1,500 nurses) (De Girolamo \& Cozza 2,000).

This retrospective study was conducted in the University Psychiatric Ward of Maggiore della Carità hospital in Novara, a town in the Piedmont region of North-Western Italy. The catchment area of the Mental Health Department has about 182,000 inhabitants, of whom $56 \%$ are resident in Novara itself. The Department has one hospital psychiatric ward (under university direction) with 14 beds and 1.7 members of staff per bed; three day hospitals (one of which is inside the hospital); two day centres, seven residential facilities (two therapeutic communities and five apartment groups, for a total of about 60 beds).

The aim of the study was to evaluate the use of IHT (considered from the point of view of psychiatric urgencies and emergencies) about 25 years after the coming into force of the Psychiatric Reform in an attempt to identify the demographic, social and clinical characteristics that are most fre- 
quently associated with this type of therapeutic provision.

\section{Materials and methods}

We selected all of the medical records relating to IHT admissions to the University Psychiatric Ward of Maggiore della Carità hospital in Novara between 1.1.1991 and 31.12.2002. These records were used to collect the following data relating to each analysed case of IHT:

- Demographic characteristics: sex, age, province of birth, province of residence;

- Psychosocial characteristics: occupation, marital status, education, cohabitation;

- Clinical information: family psychiatric history, personal psychiatric history, place of first psychiatric contact, immediate origin of patient at the time of IHT, ICD-9$\mathrm{CM}$ diagnosis (according to the system in force in the Italian National Health Service), duration of IHT, duration of admission, previous involuntary and voluntary admissions to the ward.

All of the collected data were entered in a computer database.

\section{Statistical analysis}

We first calculated the annual proportion of psychiatric admissions to the psychiatric ward, and compared it with the trend in Piedmont and Italy between 1.1.1991 and 31.12.2002.

In order to evaluate any correlations between the investigated variables, we constructed unconditioned logistic regression models to assess the correlation between the dependent dichotomy variable (a duration of admission above or below the median) and a series of independent dichotomy variables potentially capable of affecting the duration of admission.

Three models were constructed: a demographic model (independent variables: sex, age, province of birth, province of residence), a social model (independent variables: occupation, marital status, education, cohabitation), and a clinical model (independent variables: previous IHT, family psychiatric history, ICD-9-CM code, total admissions to the psychiatric ward).

All of the analyses were made using Stat Soft software.

\section{Results}

We analysed 460 cases of IHT involving 327 patients (72 patients underwent IHT more than once during the 12 years considered), for a total of 205 admissions.

Figure 1 shows the trend of IHT cases in the psychiatric ward of Maggiore della Carità hospital, Novara; Table I shows the comparison with regional and national data.

\section{Demographic characteristics}

Of the 460 episodes of IHT, 56.3\% involved men.

The overall mean age of the patients at the time of IHT was 41 years (median 39; SD 13.8). The mean age of the women was higher: 44.4 years (median 42; SD 15.2) vs 38.4 years (median 38; SD 12).

The large majority of the subjects $(87.8 \%)$ were resident in the province of Novara (Table II). 


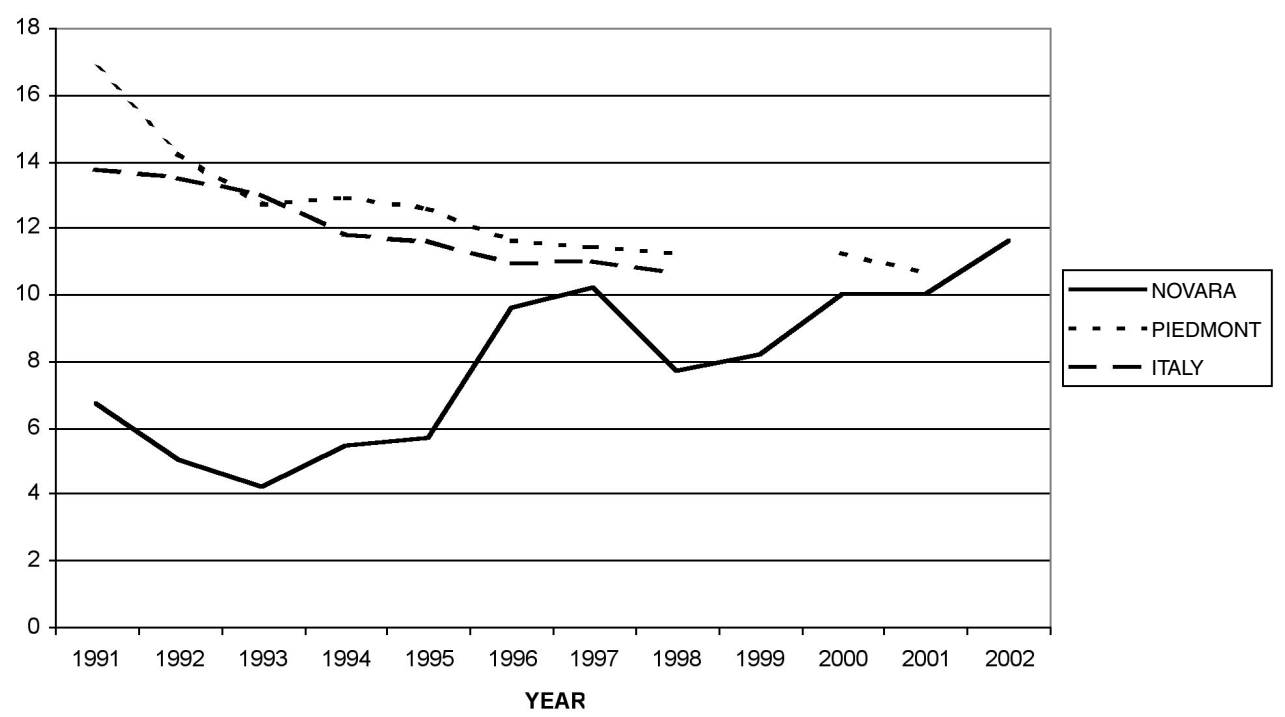

Figure 1. Trend of IHT cases in the period 1991-2002. Data are shown as percentage of IHTs on the total number of admissions

Table I

Admissions in the period 1991-2002: involuntary treatment (IHT), voluntary treatment (VHT) and total admissions

\begin{tabular}{|c|c|c|c|c|c|c|c|c|c|c|c|c|c|}
\hline & & 1991 & 1992 & 1993 & 1994 & 1995 & 1996 & 1997 & 1998 & 1999 & 2000 & 2001 & 2002 \\
\hline \multirow[t]{4}{*}{ Novara } & IHT & 31 & 23 & 25 & 27 & 29 & 48 & 46 & 34 & 38 & 45 & 49 & 65 \\
\hline & VHT & 430 & 443 & 564 & 471 & 481 & 451 & 405 & 406 & 425 & 405 & 440 & 495 \\
\hline & TOTAL & 461 & 466 & 589 & 498 & 510 & 499 & 451 & 440 & 463 & 450 & 489 & 560 \\
\hline & $\%$ IHT & 6.7 & 5 & 4.2 & 5.4 & 5.7 & 9.6 & 10.2 & 7.7 & 8.2 & 10 & 10 & 11.6 \\
\hline \multirow[t]{4}{*}{ Piedmont } & IHT & 962 & 1,099 & 1,163 & 1,274 & 1,208 & 1,170 & 1,116 & 1,092 & & & & \\
\hline & VHT & 4,790 & 6,655 & 7,999 & 8,607 & 8,382 & 8,921 & 8,673 & 8,655 & & & & \\
\hline & TOTAL & 5,752 & 7,754 & 9,162 & 9,881 & 9,590 & 10,091 & 9,789 & 9,747 & & & & \\
\hline & $\%$ IHT & 16.7 & 14.2 & 12.7 & 12.9 & 12.6 & 11.6 & 11.4 & 11.2 & & 11.2 & 10.6 & \\
\hline \multirow[t]{4}{*}{ Italy } & IHT & 14,864 & 15,557 & 15,939 & 15,141 & 15,156 & 14,882 & 15,048 & 14,781 & & & & \\
\hline & VHT & 93,773 & 99,607 & 106,305 & 113,084 & 115,501 & 121,647 & 121,755 & 124,660 & & & & \\
\hline & TOTAL & 108,637 & 115,164 & 122,244 & 128,225 & 130,657 & 136,529 & 136,803 & 139,441 & & & & \\
\hline & $\%$ IHT & 13.7 & 13.5 & 13 & 11.8 & 11.6 & 10.9 & 11 & 10.6 & & & & \\
\hline
\end{tabular}

\section{Social characteristics}

Most of the patients (55.8\%) had worked in the past but were not working at the time of admission; $29 \%$ were working at the time of IHT; and $11.3 \%$ had never worked. No occupational data were available for $3.9 \%$ of the cases $(4.6 \%$ of the women and $3 \%$ of the men).

The majority of the patients (52.8\%) were unmarried, but there was a marked difference in the proportions of unmarried men and women $(65.6 \%$ vs $36.3 \%)$. Married 
patients accounted for $24.6 \%$ of the sample (36.8\% of the women and $15.1 \%$ of the men).

No educational data were available for $9.6 \%$ of the patients; $26.7 \%$ had only attended primary school; $38 \%$ had completed compulsory middle school education; $22.9 \%$ had a high school diploma; and $2.8 \%$ were university graduates.

The cohabitation data showed that $33.5 \%$ of the patients lived with their family of origin $(23.9 \%$ of the women and $40.9 \%$ of the men), and $28.3 \%$ had their own families (42.3\% of the women and $17.4 \%$ of the men). No data were available for $13.5 \%$ of the cases; the rest of the sample consisted of subjects resident in rest homes, protected communities, long-stay healthcare facilities, lodging houses (Table II).

\section{Clinical characteristics}

The previous psychiatric history of the patients was unknown in $6.3 \%$ of the cases and unavailable in $9.8 \%$. Just over half $(51.1 \%)$ of the patients had been previously admitted to our psychiatric ward. There had been a previous contact with a public healthcare specialist In $18.2 \%$ of the cases, and a contact with a private clinic in $5.7 \%$ of cases. In $6.1 \%$ of the cases, the previous contact had been with another hospital ward and, in $1.3 \%$, with a psychiatric hospital.
Unfortunately however, the available data do not make it possible to determine whether the previous psychiatric contacts of the subjects had been of an episodic or continuous nature.

The first psychiatric contact had been admission to our psychiatric ward in $18.7 \%$ of the cases, contact with the outpatient clinic of another service in $14.7 \%$ and with our outpatient clinic in $7.8 \%$. The first contact had occurred in a psychiatric hospital in as many as $9.8 \%$ of the cases; in a hospital neurological ward in $7.8 \%$; in the Emergency Department of a general hospital or during a hospital visit in $7.2 \%$; in a psychiatric ward other than ours in $6.3 \%$; in a private clinic in $4.3 \%$; and in an infantile neuropsychiatry service in $3.7 \%$.

The immediate origin of the patients had been a public psychiatric outpatient clinic in $33.9 \%$ of the cases, the patient's home in $23.9 \%$, the Emergency Department of the general hospital in $20.1 \%$, and transfer from other hospital wards in $8 \%$.

The main clinical characteristic analysed was the ICD-9-CM diagnosis at the time of discharge. The most frequent of these diagnoses was schizophrenic psychosis $(61.1 \%$ of the total: $64.4 \%$ of the men and $57.2 \%$ of the women), followed by personality disorders (16.2\%: $16.6 \%$ of the men and $15.4 \%$ of the women), affective psychoses (5.2\%:

Table II

Demographic and social characteristics

\begin{tabular}{lccc} 
& Total group & Male & Female \\
\hline Gender & $100 \%$ & $56.3 \%$ & $43.7 \%$ \\
Average age & 41 & 38.4 & 44.4 \\
Employed (stable job) & $29 \%$ & $32.1 \%$ & $24.9 \%$ \\
Married & $24.6 \%$ & $15.1 \%$ & $36.8 \%$ \\
Unmarried & $52.8 \%$ & $65.6 \%$ & $36.3 \%$ \\
Living in parental family & $33.5 \%$ & $40.9 \%$ & $23.9 \%$ \\
Living in own family & $28.3 \%$ & $17.4 \%$ & $42.3 \%$ \\
Schizophrenic psychosis diagnosis & $61.1 \%$ & $64.4 \%$ & $57.2 \%$ \\
\hline
\end{tabular}


$1.5 \%$ of the men and $10 \%$ of the women), and alcohol dependence syndrome $(3.1 \%)$ (Figure 2).

There were a number of socio-demographic and clinical differences between the two broad groups of the patients with a diagnosis of schizophrenic psychosis and those with other diagnoses (Table III).

\section{Subjects undergoing more than one IHT}

During the 12 years considered in the study, 72 patients underwent a total of 205 involuntary admissions: an average of 2.84 per patient. For the purposes of this analysis, only the data collected at the time of the first admission were considered. Table IV shows the major differences between these patients and those undergoing a single IHT.

\section{Statistical analysis}

Three multiple logistic regression models were applied to the group of 327 patients

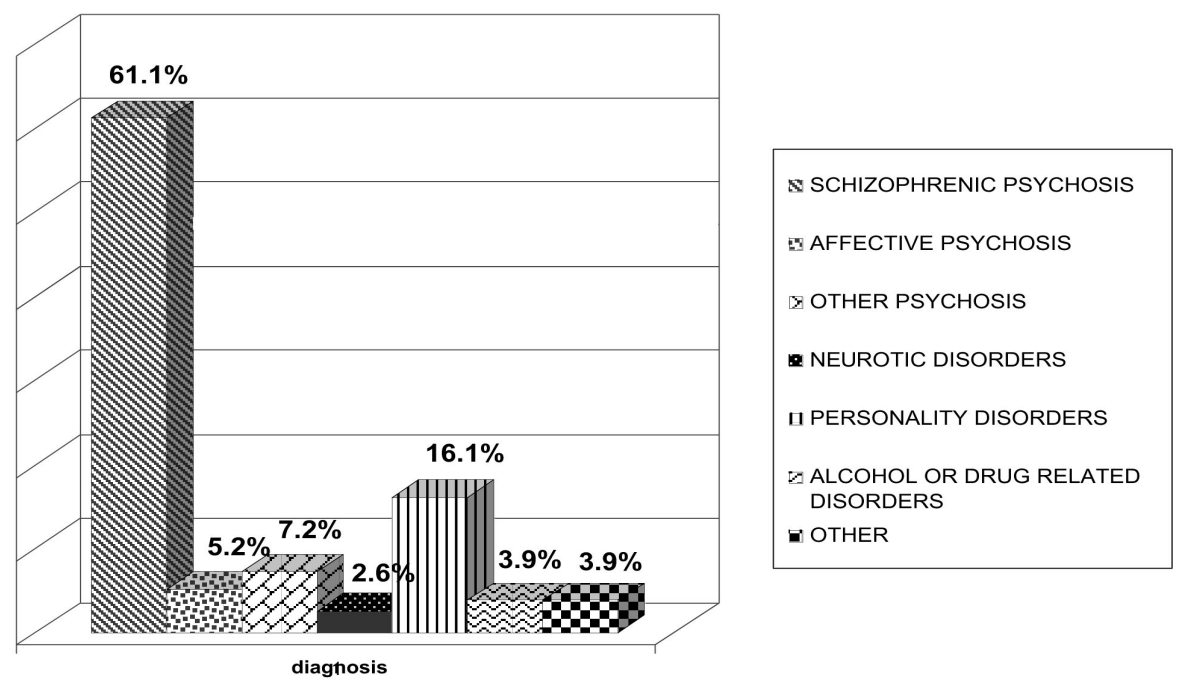

Figure 2. Diagnoses distribution. Data are shown as a percentage

Table III

Comparison between the patients with a diagnosis of schizophrenic psychosis and those with other diagnoses Schizophrenic Psychosis Other diagnosis

Average age (years)
Employed (stable job)
Unmarried
Family psychiatric history
Average length of IHT (days)
Renewed IHT
Total length of admission > 15 days
First IHT
First admission

39.8
$24.5 \%$
$57.6 \%$
$25.2 \%$
3.62
$6.4 \%$
$31.9 \%$
$51.8 \%$
$23.4 \%$

42.9
$44.9 \%$ 
who had undergone at least one IHT during the study period (Tables V-VII).

$P$ values of $<0.05$ were considered significant; those of $<0.01$ were considered highly significant.
The variables analysed in the "demographic" model were sex (male/female), age (>39 vs $\leq 39$ years), and the province of birth (Novara/other) and province of residence (Novara/other). This model revealed a high-

Table IV

Comparison between subject with a single IHT and subject with repeated IHT

\begin{tabular}{lcc} 
& Single IHT & Repeated IHT \\
\hline Males & $52.5 \%$ & $56.9 \%$ \\
Average age (years) & 42.2 & 38.5 \\
Employed (stable job) & $32.2 \%$ & $26.4 \%$ \\
Unmarried & $47.1 \%$ & $61.1 \%$ \\
Family psychiatric history & $20.4 \%$ & $29.2 \%$ \\
Schizophrenic psychosis & $51.4 \%$ & $69.4 \%$ \\
Personality disorders & $14.5 \%$ & $19.4 \%$ \\
Mood disorders & $8.2 \%$ & $1.4 \%$ \\
Alcohol addiction & $4.7 \%$ & $1.4 \%$ \\
Length of IHT $<2$ days & $56.5 \%$ & $48.6 \%$ \\
\hline
\end{tabular}

Table V

Logistic Regression - Demographic model

\begin{tabular}{lcccc} 
& Sex & Age & Province of birth & Province of residence \\
\hline p-level & 0.003222 & 0.22333 & 0.00419 & 0.003254 \\
Odds ratio (var.un) & 0.446844 & 1.417451 & 2.210477 & 3.519103 \\
-95\%CL & 0.260915 & 0.806699 & 1.281742 & 1.517386 \\
$+95 \%$ CL & 0.765267 & 2.490605 & 3.812162 & 8.161458 \\
\hline
\end{tabular}

Table VI

Logistic Regression - Social model

\begin{tabular}{lcccc} 
& Occupation & Marital status & Education & Cohabitation \\
\hline p-level & 0.782099 & 0.232352 & 0.513351 & 0.194993 \\
Odds ratio (var.un) & 0.926457 & 1.440306 & 0.833227 & 1.4569 \\
-95\%CL & 0.538058 & 0.789621 & 0.481114 & 0.822832 \\
+95\%CL & 1.595222 & 2.627187 & 1.443039 & 2.579578 \\
\hline
\end{tabular}

Table VII

Logistic regression - Clinical model

\begin{tabular}{llccc} 
& Previous IHT & $\begin{array}{c}\text { family psychiatric } \\
\text { history }\end{array}$ & $\begin{array}{c}\text { ICD-9-CM } \\
\text { code }\end{array}$ & $\begin{array}{c}\text { Total admission } \\
\text { to the psychiatric ward }\end{array}$ \\
\hline p-level & 0.762197 & 0.251288 & $1.17 \mathrm{E}-05$ & 0.793419 \\
Odds ratio (var.un) & 0.888506 & 1.358737 & 3.090737 & 0.929085 \\
-95\%CL & 0.41195 & 0.803168 & 1.862449 & 0.534622 \\
+95\%CL & 1.91636 & 2.298604 & 5.129085 & 1.614597 \\
\hline
\end{tabular}


ly significant correlation between male sex and a duration of admission of less than 12 days ( $\mathrm{p}<0.01)$, with males being "protected" against the likelihood of an admission exceeding 12 days $(\mathrm{OR}=0.45)$.

Highly significant correlations were also found with the province of birth and the province of residence: the subjects born in the province of Novara had a more than twofold higher risk of being admitted for more than 12 days than those born elsewhere $(\mathrm{p}<0.01)$, and those resident in the province of Novara had a 3.5-fold higher risk of being admitted for more than 12 days than those born elsewhere $(\mathrm{p}<0.01)$ (Table V).

The variables analysed in the "social" model were occupation (employed/unemployed), marital status (unmarried/other), education (up to the end of middle school/ beyond the end of middle school), and cohabitation (own family or family of origin/ other). None of these variables significantly influenced the total duration of admission (Table VI).

The variables analysed in the "clinical" model were previous IHT (yes/no), a psychiatric family history (yes/no or unknown), ICD-9-CM diagnosis (schizophrenic psychosis/other), and the total number of admissions to the Novara psychiatric ward $(1 />1)$. This model showed that the subjects with a diagnosis of schizophrenic psychosis (ICD-9-CM code 295) had an approximately 3-fold higher risk of being admitted for more than 12 days $(\mathrm{p}<0.01)$ (Table VII).

\section{Discussion}

Our analysis shows that the percentage of IHT admissions in Novara was below the national average for many years, but began to approach it towards the end of the study period. On the other hand, although the national trend was characterised by a constant increase in the total number of psychiatric admissions, the number of IHT admissions remained stable and their relative proportion therefore decreased. This latter phenomenon is attributable to a progressive national uniformity in the number of beds available in residential facilities (Crepet 1989, Crepet 1992), as confirmed by the fact that the percentage of IHT admissions in Lombardy (the region bordering Piedmont) was $12.1 \%$ in $1998,12.6 \%$ in 1999 and $11.8 \%$ in 2000 (Gandini \& Lora 2001, Gandini \& Lora 2002).

It is also worth pointing out that, in comparison with the year preceding the reform, there was a reduction of about $60 \%$ in the number of IHT admissions in the period immediately following the closure of Psychiatric Hospitals in Italy (which started in 1978), whereas the number of voluntary admissions increased by about $30 \%$ (Consiglio Nazionale delle Ricerche (National Research Council, 1981).

The IHT admissions in our sample were most frequently associated with schizophrenic psychoses $(61.1 \%)$. In comparison with those affected by other psychiatric disorders, schizophrenic subjects are more frequently unmarried or live in a narrower relational context; family members are potentially capable of reporting a situation before it becomes a psychiatric urgency that can sometimes only be confronted by means of IHT. Logistic regression analysis also showed that schizophrenia is associated with a higher risk of longer-lasting admissions, probably because it takes longer to ensure the compensation of a psychotic exacerbation than the stabilisation of other psychopathological conditions (as previously demonstrated by Arcuni \& 
Asaad 1989) and is very often related to the condition of relapse (Sullivan et al. 1993, Segal et al. 1998, Saarento et al. 1998, Dhossche et al. 1998, Fennig et al. 1999).

A health report published by the Piedmont Regional Council has highlighted the fact that schizophrenic patients are at higher risk of being admitted than subjects with other psychiatric disorders (Regione Piemonte 2001).

In general, the finding of this study that merits greatest attention is the increase in the number of IHT admissions recorded during the last years of the study period. This can be explained by the fact that the residential facilities available to our mental Health Department (particularly therapeutic communities) are largely occupied by patients who lived in Psychiatric Hospitals before the 1978 reform, or subjects who are unlikely to be re-educated or rehabilitated, thus limiting the availability of beds for people whose symptoms have emerged more recently, and favouring a "revolving door" phenomenon in the case of patients who cannot immediately return to their homes at the time of hospital discharge.

While awaiting the provision of additional residential facilities, one means of facing this situation could be to increase the use of alternatives, such as day centres and day hospitals, and strengthen the supply of domiciliary medical and nursing services, in order to construct a protective fence around difficult patients and implement suitable therapeutic approaches earlier, before arriving at the point of emergency IHT. The more effective the healthcare support, and the better the network of significant figures constructed around it, the less will be the need for urgent hospital admissions.

The closure of the Psychiatric Hospitals, which was a fundamental juridical/ideo- logical step in overcoming the previous organisation, did not lead to the concrete provision of adequate instruments and methods for the local management of psychiatry, and this contributed to making the Italian psychiatric scenario extremely heterogeneous (Censis 1983) because each region was faced with the need to create its own organisational structure. By 1981, Piedmont's regional council had identified "applicative approaches" aimed at transforming its psychiatric hospital-based organisation of mental health into a territorially based service, including its subdivision into zones, the integration of preventive, diagnostic, therapeutic and rehabilitation activities, the establishment of working teams, and the prevalence of outpatient treatments (Regione Piemonte 1981).

On the basis of our data, we can say that IHT remains relatively sporadic in the context of psychiatric admissions, and recourse to it is only made after the failure of every other therapeutic strategy: it is therefore an extreme resource (Vecchietti 1981). When IHT is inevitable, every attempt is made to shorten its duration by means of the revocation of the order. Furthermore, during the course of an IHT admission, the use of physical containment is very rare, and is only lawful when there is a "state of necessity" and must then be proportionate to the danger it is intended to avoid, in such a way that the damage caused is no greater than that threatened (Castiglioni \& Flores 1987). In a paper on the subject of consent to psychiatric health treatment, Girolami analysed the "totalising" nature of psychiatric disease insofar as it involves all of the reality of a person and jeopardises his/her faculty to consent to treatment: juridically, a psychiatric patient is considered a weak subject, but one who is capable, alone or with the aid of third 
parties, of performing many juridically relevant acts and facts (Girolami 1997).

\section{References}

Arcuni OJ, Asaad G. Voluntary and involuntary schizophrenic patient admission on the same general hospital psychiatric unit. Gen Hosp Psychiatry 1989; 11(6): 393396.

Castiglioni R, Flores A. Sull'uso dei mezzi di contenzione in ambiente psichiatrico. Considerazioni giuridiche e medico-legali. Rivista Sperimentale di Freniatria 1987; CXI(1): 137-146.

CENSIS - CISEFF. Indagine CENSIS - CISEFF sulla attuazione della riforma psichiatrica e sul destino dei dimessi dagli o.p. Roma: Edizioni Paoline; 1983.

Consiglio Nazionale delle Ricerche. La riforma psichiatrica, prima fase di attuazione. Roma: Il Pensiero Scientifico Editore; 1981.

Crepet P. La transizione dell'assistenza psichiatrica in Italia. Nuovi elementi per una valutazione epidemiologica. Rivista Sperimentale di Freniatria 1989; 113: 606-30.

Crepet P. L'andamento del ricovero psichiatrico in Italia negli ultimi venti anni. Analisi dei dati aggregati su base nazionale e regionale. Rivista Sperimentale di Freniatria 1992; 116:675-87.

De Girolamo G, Cozza M. The italian psychiatric reform. A 20 year perspectiva. International Journal of Law and Psychiatry 2000; 23:197-214.

Dhossche DM, Ghani SO. A study on recidivism in the psychiatric emergency room. Ann Clin Psychiatry 1998; 10(2): 59-67.

Fennig S, Rabinowitz J, Fennig S. Involuntary first admission of patients with schizophrenia as a predictor of future admissions. Psychiatr Serv 1999; 59: 1049-1052.

Gandini A, Lora A. I servizi psichiatrici della regione Lombardia 1999. Regione Lombardia Sanità; 2001.

Gandini A, Lora A. I servizi psichiatrici della regione Lombardia 2000. Regione Lombardia Sanità; 2002.

Giampieri E, Ratti A, Beretta A, Mattavelli C, Ferrarini E, Pruneri C, Carta I. Determinations of hospitalization from psychiatric ER from S. Gerardo hospital in Monza: epidemiological cross-sectional study. Epidemiologia $e$ Psichiatria Sociale 2002; 11(4): 266-276.

Girolami P. Alcune considerazioni in tema di consenso al trattamento sanitario con particolare riguardo all' ambito psichiatrico. Rivista Italiana di Medicina Legale 1997; XIX: 287-311.

Hattori I, Higashi T. Socioeconomic and familial factors in the involuntary hospitalization of patients with schizophrenia. Psychiatric Clinical Neurosciences 2004; 58(1): $8-15$.

Kozumplik O, Jukic V, Goreta M. Involuntary hospitalization of patients with mental disorders in Vrapce Psychiatric Hospital: five years of implementation of the first Croatian law on protection of persons with mental disorders. Croatian Medicine Journal 2003; 44: 601-5.

Legge 23 dicembre 1978, $\mathrm{n}^{\circ} 833$ Istituzione Servizio Sanitario Nazionale - Gazzetta Ufficiale della Repubblica Italiana $\mathrm{n}^{\circ} 360$ del 28 dicembre 1978.

Munk-Jorgensen P, Mortenseen PB, Machon RA. Hospiatlization patterns in schizophrenia. A 13-year follow-up. Schizophr Res 1991; 4: 1-9.

Piccinelli M, Politi P, Barale F. Focus on psychiatry in Italy. Br J Psychiatry 2002; 181:538-544.

Regione Piemonte. Documentazione per il convegno 'Psichiatria e Salute mentale nel governo democratico della salute’. Viareggio; 1981.

Regione Piemonte. La salute in Piemonte. Anno 2000. Torino: giugno; 2001.

Regione Piemonte, ASL 13, ASO Maggiore della Carità, Galliate e Novara. La carta dei servizi del Dipartimento di Salute Mentale Interaziendale Sud.

Regione Piemonte, Conferenza dei Dipartimenti di Salute Mentale Quadrante Nord Est. Carta dei servizi per la Salute Mentale.

Repubblica Italiana, Ministero della salute. Piano Sanitario Nazionale 2003-2005.

Saarento O, Hakko H, Joukamaa M. Repeated use of psychiatric emergency out-patient services among new patients: a 3 year follow-up study. Acta Psychiatr Scand 1998; 98: 276-282.

Sanguineti VR, Samuel SE, Schwartz SL, Robeson MR. Retrospective study of 2200 involuntary psychiatric admissions and readmissions. Am J Psychiatry 1996; 153(3): 392-396.

Schnyder U, Klaghofer R, Leuthold A, Buddeberg C. Characteristics of psychiatric emergencies and the choice of intervention strategies. Acta Psychiatr Scand 1999; 99(3): 179-187.

Segal SP, Akutsu PD, Watson MA. Factors associated with involuntary return to a psychiatric emergency service within 12 months. Psychiatric Services 1998; 49: 12121217. 
Slagg NB. Characteristics of emergency room patients that predict hospitalization or disposition to alternative treatments. Hosp Community Psychiatry 1993; 44(3): 2526.

Sostero M, Papa R, Borghi C et al. Studio epidemiologico sui pazienti ricoverati in regime di TSO presso la UOP del Policlinico di Milano, dagli "L'epidemiologia per la psichiatria sociale", Atti del Primo Congresso Nazionale della Società Italiana di Epidemiologia Psichiatrica, Genova 7-9 ottobre 1993, edizioni Aristea Congressi, Genova.

Steinert T, Schmid P. Effect of voluntariness of partecipation in treatment on short-term outcome of inpatients with schizophrenia. Psychiatric Services 2004, 55: 786791.

Sullivan PF, Bulik CM, Forman SD, Mezzich JE. Characteristics of repeat users of a psychiatric emergency service. Hosp Community Psychiatry 1993; 44(4): 376-380.

Vecchietti AM. Evoluzione della legislazione psichiatrica italiana dalla legge 36/1904 alla legge 833/1978. Rivista Italiana di Medicina Legale 1981; III: 115-142.
Way BB, Banks S. Clinical factors related to admission and release decisions in psychiatric emergency services. Psychiatric services 2001; 52(2): 214-218.

Wingerson D, Russo J, Ries R et al. Use of psychiatric emergency services and enrollment status in a public managed mental health care plan. Psychiatric services 2001; 52(11): 1494-1501.

World Health Organization. World Health Report. Mental Health: New Understanding, New Hope. Ginevra: WHO; 2001.

Address of correspondence:

Patrizia Zeppegno

Cattedra di Psichiatria

Department of Medical Sciences

Medical School of Novara

University of Eastern Piedmont, "Amedeo Avogadro"

Via Gnifetti 8

28100 Novara

ITALY

patrizia.zeppegno@med.unipmn.it 